Hyun-Jai Cho $\cdot$ In-Ho Chae $\cdot$ Kyung-Woo Park

Jae-Ran Ju $\cdot$ Seil Oh $\cdot$ Myoung-Mook Lee

Young-Bae Park

\title{
Functional polymorphism in the promoter region of the gelatinase B gene in relation to coronary artery disease and restenosis after percutaneous coronary intervention
}

Received: September 28, 2001 / Accepted: November 14, 2001

\begin{abstract}
The matrix metalloproteinases appear to play an important role in the development and progression of atherosclerotic lesions. We studied the $\mathrm{C}-1562 \mathrm{~T}$ polymorphism of the gelatinase $\mathrm{B}$ promoter in relation to coronary artery disease and restenosis after a percutaneous coronary intervention (PCI) in Koreans. To determine the frequency of the $\mathrm{C}-1562 \mathrm{~T}$ allele, we examined 63 patients with coronary artery disease who underwent both PCI and 6-month follow-up coronary angiograms (CAGs), and 67 control patients with a normal CAG with respect to their clinical data and genotype. Frequencies of the $\mathrm{C} / \mathrm{C}$ homozygotes and the non-C/C heterozygotes and homozygotes $(\mathrm{C} / \mathrm{T}$ and $\mathrm{T} / \mathrm{T})$ were $94 \%$ and $6 \%$ in the normal CAG group, and $76.2 \%$ and $23.8 \%$ in the patient group, respectively. This gave a relative risk of 0.203 (95\% CI: $0.063-0.651, P=0.005)$ for coronary artery disease when the $\mathrm{C} / \mathrm{C}$ genotype was compared with the non-C/C genotype. In the patient groups, the allele frequencies of the $\mathrm{C} / \mathrm{C}$ and non- $\mathrm{C} / \mathrm{C}$ were $80 \%$ and $20 \%$ in the nonrestenotic subgroup, and $71.4 \%$ and $28.6 \%$ in the restenotic subgroup $(P=0.554)$. No T/T homozygote was found in any of the groups. We conclude that $\mathrm{C} / \mathrm{C}$ homozygosity is a potential genetic protective factor for coronary artery disease in Koreans.
\end{abstract}

Key words Gelatinase B · Polymorphism · Matrix metalloproteinase $\cdot$ Coronary artery disease $\cdot$ Atherosclerosis

H.-J. Cho · I.-H. Chae · K.-W. Park. · J.-R. Ju · S. Oh · M.-M. Lee · Y.-B. Park

Heart Research Institute, Medical Research Center, Seoul National University, Seoul, Korea

H.-J. Cho · I.-H. Chae $(\varangle) \cdot$ K.-W. Park · S. Oh · M.-M. Lee ·

Y.-B. Park

Department of Internal Medicine, Seoul National University College of Medicine, 28 Yongon-dong Chongno-gu, Seoul 110-744, Korea

Tel. +82-2-760-2684; Fax +82-2-766-8944

e-mail: ihchae@snu.ac.kr

H.-J. Cho $\cdot$ I.-H. Chae $\cdot$ K.-W. Park · J.-R. Ju $\cdot$ S. Oh $\cdot$ M.-M. Lee Y.-B. Park

Cardiovascular Research Laboratory, Clinical Research Institute,

Seoul National University Hospital, Seoul, Korea

\section{Introduction}

The matrix metalloproteinases (MMPs), a family of zincdependent enzymes that have proteolytic activity against connective tissue proteins, appear to play an important role in the development and progression of atherosclerotic lesions and are contributors to intimal growth and restenosis after stenting (Bendek et al. 1996; Ye 2000; Feldman et al. 2001). Three functional polymorphisms of MMPs are known to be related to coronary artery disease, i.e., MMP3, MMP-9, and MMP-12 (Ye et al. 1995; Terashima et al. 1999; Zhang et al. 1999; Jormsjo et al. 2000).

Gelatinase B (also known as 92-kDa type IV collagenase, or MMP-9) is a member of the MMP family. Gelatinase B is found to be highly expressed in the disruption-prone region of atherosclerotic plaques. It has broad substrate specificity, being particularly active against gelatins and type IV collagen; therefore, it plays a key role in extracellular matrix degradation. This is required for cell migration into the intima after an arterial injury (Pauly et al. 1994; Newby et al. 1994).

The functional C-1562T polymophism of the gelatinase B promoter was studied for its effects on atherosclerotic severity in a patient with coronary artery disease (Zhang et al. 1999), but no definite relation to coronary artery disease could be found in the general population. Consequently, we studied the C-1562T polymorphism of the gelatinase B promoter in its relation to coronary artery disease by comparing a proven normal coronary angiogram $(\mathrm{CAG})$ group with a coronary artery disease patient group and also by examining the development of restenosis after a percutaneous coronary intervention (PCI) in the patient group.

\section{Patients and methods}

Patients and control individuals

A total of 130 subjects who were available for genomic DNA analysis were enrolled in this study. All participants 
Table 1. Clinical characteristics according to coronary angiogram and restenosis

\begin{tabular}{|c|c|c|c|c|c|}
\hline & \multirow[b]{2}{*}{$\begin{array}{l}\text { Total } \\
(n=130)\end{array}$} & \multirow[b]{2}{*}{$\begin{array}{l}\text { Normal CAG } \\
(n=67)\end{array}$} & \multicolumn{2}{|c|}{ Coronary artery disease patient } & \multirow[b]{2}{*}{$P$ value* } \\
\hline & & & $\begin{array}{l}\text { restenosis }(-) \\
(n=35)\end{array}$ & $\begin{array}{l}\text { restenosis }(+) \\
(n=28)\end{array}$ & \\
\hline Male (\%) & $58 \%$ & $53 \%$ & $61 \%$ & $58 \%$ & NS \\
\hline Age (years) & $58 \pm 10$ & $56 \pm 10$ & $58 \pm 10$ & $60 \pm 11$ & NS \\
\hline Diabetes (\%) & $26 \%$ & $26 \%$ & $32 \%$ & $20 \%$ & NS \\
\hline Hypertension (\%) & $42 \%$ & $38 \%$ & $45 \%$ & $56 \%$ & NS \\
\hline Smoking (\%) & $32 \%$ & $32 \%$ & $32 \%$ & $31 \%$ & NS \\
\hline Total cholesterol (mg/dl) & $197 \pm 40$ & $196 \pm 41$ & $199 \pm 40$ & $193 \pm 36$ & NS \\
\hline Triglyceride $(\mathrm{mg} / \mathrm{dl})$ & $141 \pm 76$ & $135 \pm 70$ & $135 \pm 54$ & $161 \pm 103$ & NS \\
\hline HDL cholesterol (mg/dl) & $44 \pm 12$ & $44 \pm 13$ & $46 \pm 12$ & $40 \pm 9$ & NS \\
\hline LDL cholesterol (mg/dl) & $125 \pm 35$ & $126 \pm 37$ & $125 \pm 34$ & $121 \pm 33$ & NS \\
\hline
\end{tabular}

CAG, coronary angiogram; HDL, high-density lipoprotein; LDL, low-density lipoprotein

$*$ NS, nonsignificant $(P$ value $>0.05)$

were Korean nationals. The study population was composed of 63 patients with coronary artery disease who had undergone both PCI and a 6-month CAG follow-up, as well as 67 control patients in a normal CAG group who had atypical chest pains and were admitted to the Seoul National University Hospital between January 1997 and July 2001. None of the normal CAG control individuals had insignificant coronary artery stenosis. Insignificant coronary artery stenosis was excluded in this study. The coronary artery disease patient group expressed a stenosis of $\geq 50 \%$ in at least one epicardial artery and ischemic chest pain. The restenotic subgroup was defined as having a restenosis of $\geq 50 \%$ at the PCI site and a clinically redeveloped chest pain. We also examined clinical and laboratory characteristics such as age, gender, diabetes, hypertension, smoking, total cholesterol, triglyceride, high-density lipoprotein cholesterol and low-density lipoprotein cholesterol. All patients had given informed consent for genetic and clinical examination before CAG.

Analysis of the polymorphism

Genomic DNA was extracted from peripheral blood leukocytes according to a standard protocol (Sambrook et al. 1989). We performed the polymerase chain reaction (PCR) by using the primers that were designed according to a previous study (Zhang et al. 1999). Subsequently, the PCR products were digested with an appropriate restriction enzyme, $B b u \mathrm{I}$, and fractionated on a $1.5 \%$ agarose gel. The $\mathrm{T}$ allele at the -1562 polymorphic site generated two fragments using BbuI. Genotypes were scored according to the pattern of the DNA bands.

\section{Statistical analysis}

Data were analyzed using Statistical Package for the Social Sciences statistical software. $\chi^{2}$ analysis was used to test for the deviation in the genotype distribution of the HardyWeinberg equilibrium and the Fisher's exact test was used to determine whether there was any significant difference in
Table 2. $\mathrm{C} / \mathrm{C}$ versus non- $\mathrm{C} / \mathrm{C}(\mathrm{C} / \mathrm{T}$ and $\mathrm{T} / \mathrm{T})$ in relation to coronary artery disease and allele frequencies

\begin{tabular}{lll}
\hline & $\begin{array}{l}\text { Normal CAG } \\
(n=67)\end{array}$ & $\begin{array}{l}\text { Coronary artery } \\
\text { disease patient } \\
(n=63)\end{array}$ \\
\hline $\mathrm{C} / \mathrm{C}$ & $63(94 \%)$ & $48(76.2 \%)^{*}$ \\
Non-C/C $(\mathrm{C} / \mathrm{T}+\mathrm{T} / \mathrm{T})$ & $4+0(6 \%)$ & $15+0(23.8 \%)$ \\
$\mathrm{C}$ allele frequency & 0.93 & 0.88
\end{tabular}

* Odds ratio of $\mathrm{C} / \mathrm{C}$ for coronary artery disease: 0.203 (95\% C.I.: $0.063-0.651, P$ value: 0.005 )

genotype frequencies between normal CAG control group and patient groups. The $\chi^{2}$ test and the one-way analysis of variance (ANOVA) test was used for a clinical and laboratory characteristic analysis among the groups. The value of $P<0.05$ was taken to be statistically significant.

\section{Results}

The characteristics of the normal CAG subjects and the patients who were subgrouped according to the presence of restenosis are shown in Table 1. There were no significant differences in the clinical and laboratory characteristics between the groups. The genotypic and allelic frequencies of the $\mathrm{C}-1562 \mathrm{~T}$ polymorphism of the gelatinase $\mathrm{B}$ promoter gene are summarized in Table 2 . We did not find a T/T genotype in this study. These data are consistent with the distribution predicted by the Hardy-Weinberg equilibrium (the $\mathrm{T} / \mathrm{T}$ allele was expected in 0.69 persons among the 130 subjects, $P$ value: 0.67 ).

The allele frequency in normal Korean CAG subjects was different from that which has been previously reported in Caucasians, but the frequency in the coronary artery disease patient population was similar to Caucasian patients (Zhang et al. 1999). In healthy Caucasians, the frequency of the $\mathrm{C}$ allele was 0.87 and in Caucasian coronary artery disease patients the frequency was 0.86 . In Koreans, the $\mathrm{C} /$ $\mathrm{C}$ genotype was significantly more frequent in normal CAG 
Table 3. $\mathrm{C} / \mathrm{C}$ versus non- $\mathrm{C} / \mathrm{C}(\mathrm{C} / \mathrm{T}$ and $\mathrm{T} / \mathrm{T})$ in relation to restenosis after PCI

\begin{tabular}{lll}
\hline & $\begin{array}{l}\text { PCI restenosis }(-) \\
(n=35)\end{array}$ & $\begin{array}{l}\text { PCI restenosis }(+) \\
(n=28)\end{array}$ \\
\hline C/C & $28(80 \%)$ & $20(71.4 \%)$ \\
Non-C/C & $7(20 \%)$ & $8(28.6 \%)$ \\
\hline
\end{tabular}

$P$ value: 0.554

PCI, percutaneous coronary intervention

subjects than in coronary artery disease patients. The odds ratio of the $\mathrm{C} / \mathrm{C}$ versus the non- $\mathrm{C} / \mathrm{C}$ genotype for coronary artery disease was significantly low. The frequency of the $\mathrm{C} /$ $\mathrm{C}$ genotype in coronary artery disease patients was similar to that of Caucasian patients because the $\mathrm{C} / \mathrm{C}$ genotype was reported to be $73.2 \%$ (Zhang et al. 1999). However, in comparing the nonrestenotic group with the restenotic group, no significant genotypic difference was found (see Table 3.)

\section{Discussion}

At least 20 human MMPs have been identified. Some can be potentially implicated in both the atherogenic process and in the precipitation of acute coronary syndromes as a result of the regulation of connective tissue remodeling process (Dollery et al. 1995). There are a number of regulatory mechanisms that can influence the ultimate impact of an MMP on extracellular matrix degradation. It appears that, for most MMPs, the key step is a transcriptional regulation because most MMP genes are expressed only when there is active physiological or pathological tissue remodeling taking place (Matrisian 1990; Fini et al. 1998).

Expression of gelatinase B is also regulated primarily at the transcription level. The $\mathrm{C}-1562 \mathrm{~T}$ polymorphic site is known to be an important regulatory element that appears to be a binding site for a transcription repressor protein, switching from $\mathrm{C}$ to $\mathrm{T}$, which results in the loss in the binding of the nuclear protein to this region of the gelatinase $\mathrm{B}$ gene promoter and an increase in the transcriptional activity in macrophages (Zhang et al. 1999).

An association of the C-1562T polymorphism with the degree of severity of coronary atherosclerosis was detected in a Caucasian study, but there was not a definite association with the development of atherosclerosis when normal subjects were compared with patients (Zhang et al. 1999). In comparison with the Caucasian study, the normal control subjects of the present study had normal CAGs and mainly atypical chest pain. We excluded subjects who had an insignificant coronary lesion, so that the normal control subjects of this study were a typically normal CAG control population and not just a normal healthy population. In addition, baseline characteristics such as lipid levels and clinical risk factor for coronary artery disease were not significantly different between the normal control group and the patient groups. In this study, we identified the $\mathrm{C} / \mathrm{C}$ genotype, and a low transcriptional activity, that is associated with the absence of atherosclerosis when we compared the coronary artery disease patients with the normal Korean CAG control subjects. Although the precise underlying mechanisms are unclear, it is plausible that lower gelatinase B expression associated with the $\mathrm{C} / \mathrm{C}$ genotype attenuates pathological matrix remodeling in atheroclerotic plaque and smooth muscle migration during atherogenesis. However, we did not observe an association with restenosis after PCI. Our study was limited by a relatively small sample size that has weak statistical power; therefore, we cannot exclude the possibility of obtaining false positive results in the genetic study previously mentioned (Risch 2000). This finding has a possibility of linkage disequilibrium with another lociassociated atherogenesis.

In conclusion, the $\mathrm{C}$ allele and the $\mathrm{C} / \mathrm{C}$ genotype are predominantly found in Koreans, but the $\mathrm{T} / \mathrm{T}$ genotype is very rare. The $\mathrm{C} / \mathrm{C}$ genotype is a possible genetic marker for a protective effect in coronary artery disease, but has no significant effect in restenosis after PCI. Further studies are now indicated to validate the differences that appear to be found between Caucasians and Asians.

Acknowledgment This study was supported by a grant of the Korea Health 21 R\&D project, Ministry of Health and Welfare, Republic of Korea (HMP-00-CH-01-0001).

\section{References}

Bendeck MP, Irvin C, Reidy MA (1996) Inhibition of matrix metalloproteinase activity inhibits smooth muscle migration but not neointimal thickening after arterial injury. Circ Res 78:38-43

Dollery CM, McEwan JR, Henney AM (1995) Matrix metalloproteinases and cardiovascular disease. Circ Res 77:863-868

Fieldman LJ, Mazighi M, Scheuble A, Deux JF, Benedetti ED, Commander CB, Brambilia E, Henin D, Steg PG, Jacob MP (2001) Differential expression of matrix metalloproteinase after stent implantation and balloon angioplasty in the hypercholesterolemic rabbit. Circulation 103:3117-3122

Fini ME, Cook JR, Mohan R, Brinckerhoff, CE (1998) Regulation of matrix metalloproteinase gene expression. In: Parks WC, Mecham RP (eds) Matrix metalloproteinases. Academic Press, Boston, pp 300-356

Jormsjo S, Ye S, Moritz J, Walter DH, Dimmeler S, Zeiher AM, Henney A, Hamstern A, Eriksson P (2000) Allele-specific regulation of matrix metalloproteinase- 12 gene activity is associated with coronary artery luminal dimensions in diabetic patients with manifest coronary artery disease. Circ Res 86:998-1003

Matrisian LM (1990) Metalloproteinases and their inhibitors in matrix remodeling Trends Genet 6:121-125

Newby AC, Southgate KM, Davies M (1994) Extracellular matrix degrading metalloproteinases in the pathogenesis of arteriosclerosis. Basic Res Cardiol 89 (Suppl 1):59-70

Pauly RR, Passaniti A, Bilato C, Monticone R, Cheng L, Papadopoulos N, Gluzband YA, Smith L, Weinstein C, Lakatta EG, Crow MT (1994) Migration of cultured vascular smooth muscle cells through a basement membrane barrier requires type IV collagenase activity and is inhibited by cellular differentiation. Circ Res 75:4154

Risch NJ (2000) Searching for genetic determinants in the new millennium. Nature 405:847-856

Sambrook J, Fritsh EF, Maniatis T (1989) Analysis and cloning of leukaryotic genomic DNA. In: Ford N, Nolan C, Ferguson M (eds) Molecular cloning, 2nd edn, vol 9 Cold Spring Harbor Laboratory Press, New York, pp 16-23

Terashima M, Akita H, Kanazawa K, Inoue N, Yamada S, Ito K, Matsuda Y, Takai E, Iwai C, Kurogane H, Yoshida Y, Yokoyama M 
(1999) Stromelysin promoter $5 \mathrm{~A} / 6 \mathrm{~A}$ polymorphism is associated with acute myocardial infarction. Circulation 99:2717-2719

Ye S (2000) Polymorphism in matrix metalloproteinase gene promoters: implication in regulation of gene expression and susceptibility of various diseases. Matrix Biol 19:623-629

Ye S, Watts GF, Mandalia S, Humphries SE, Henney AM (1995) Genetic variation in the human stromelysin promoter is associated with progression of coronary atherosclerosis. Br Heart J 73:209215

Zhang B, Ye S, Herrmann SM, Eriksson P, Matt M, Evans A, Arveiler D, Luc G, Cambien F, Hamstern A, Watkins H, Henney AM (1999) Functional polymorphism in the regulatory region of gelatinase $\mathrm{B}$ gene in relation to severity of coronary atherosclerosis. Circulation 99:1788-1794 